\title{
Peace at Heart
}

Caroline Nguyen

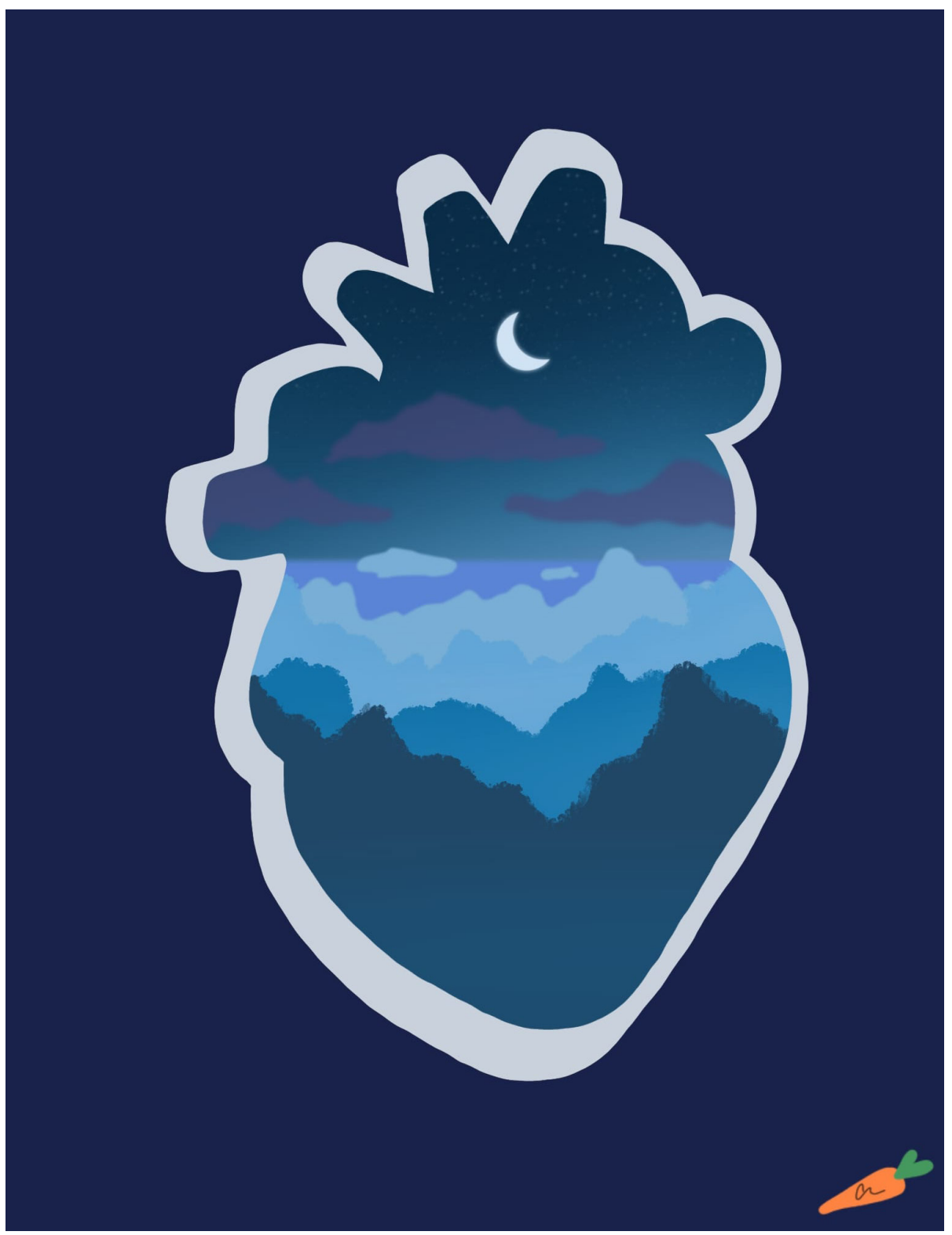

Everything in life is connected with each other; and this includes nature and our health. However with the digital world on the rise, a lot of people are feeling a disconnect with the universe. I named this piece, "'Peace at Heart," because being in nature brings us comfort and makes us happier, but not only that, it also contributes to our physical well-being. There is another meaning to my work that is very personal to me, and it represents that my late uncle is finally at peace and reunited with nature after suffering from cardiovascular disease. 